\title{
Materiais compósitos particulados em matriz epóxi reforçados com serragem, cimento e silicato de magnésio
}

\author{
Particulate composite material in epoxy matrix \\ reinforced with sawdust, cement and magnesium silicate
} Zélia Maria Velloso Missagia
Universidade Federal de São João
Del-Rei
São João Del Rei - MG - Brasil
Júlio Cesar Santos
Universidade Federal de São João
Del-Rei
São João Del Rei - MG - Brasil

Túlio Hallak Panzera Universidade Federal de São João São João Del Rei - MG - Brasil

Lincoln Cardoso Brandão Universidade Federal de São João

São João Del Rei - MG - Brasil

Diogo Aparecido Lopes Silva Universidade de São Paulo São Carlos - SC - Brasil

André Luis Christoforo Universidade Federal de São João

São João Del Rei - MG - Brasil

Recebido em 17/07/13 Aceito em 14/07/13

\section{Zélia Maria Velloso Missagia \\ Júlio Cesar Santos \\ Túlio Hallak Panzera \\ Lincoln Cardoso Brandão \\ Diogo Aparecido Lopes Silva \\ André Luis Christoforo}

\section{Resumo}

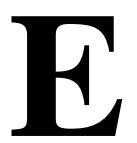

ste trabalho tem como objetivo investigar propriedades físicas (densidade volumétrica e absorção de água) e mecânicas (módulo de elasticidade e resistência à compressão) de materiais compósitos particulados em matriz epóxi reforçados com serragem de madeira, cimento Portland e silicato de magnésio. Um planejamento experimental inicial foi elaborado envolvendo apenas a resina epóxi e a serragem de madeira. Posteriormente, elegeu-se o tratamento que forneceu os maiores valores para o módulo de elasticidade na compressão. Sobre a condição escolhida, foram desenvolvidas outras quatro, incorporando-se $10 \%$ e $20 \%$ em frações mássicas de partículas de silicato de magnésio e cimento Portland sobre a resina. Os compostos com $30 \%$ de serragem de madeira Eucalyptus grandis e faixa granulométrica 5080 US-Tyler apresentaram os melhores valores para o módulo de elasticidade na compressão, sendo utilizados como condição de referência para a inclusão das partículas de cimento e do talco. O emprego do cimento nos compostos conferiu aumentos significativos no módulo de elasticidade à compressão, densidade e redução na absorção de água.

Palavras-chave: Serragem. Cimento. Silicato de magnésio. Compressão. Planejamento de experimentos.

\section{Abstract}

This study aims to investigate the physical properties (bulk density, and water absorption) and mechanical properties (modulus of elasticity, and compressive strength) of particulate composite materials in epoxy resin matrix reinforced with sawdust, Portland cement and magnesium silicate. An initial experimental design was developed involving only the epoxy resin and sawdust. Subsequently, the decision was made to choose the treatment that gave the highest values for the modulus of elasticity in compression. From this chosen condition, four other conditions were developed, incorporating $10 \%$ to $20 \%$ in mass fraction of particles of magnesium silicate and Portland cement $(P C-V)$ in the resin. Compounds with $30 \%$ of Eucalyptus grandis sawdust and range of particle size 50-80 US-Tyler showed the best values for the modulus of elasticity in compression, which was used as a reference condition for the inclusion of cement and silicate particles. The use of cement in the compounds produced a significant increase in the compressive modulus of elasticity, bulk density and reduced water absorption.

Keywords: Sawdust. Cement. Magnesium silicate. Compression. Design of experiments. 


\section{Introdução}

Os resíduos oriundos do processamento da madeira têm-se apresentado como agravante contribuição à geração de impactos ambientais, motivando pesquisas que visem a soluções a essa problemática de dimensões mundiais.

Entre esses resíduos, destaca-se o da madeira como pó de lixa e serragem, por serem materiais de baixa densidade, o que exige maior espaço para estocagem, e por serem de fácil combustão (YAMAJI; BOUDELLE, 2004).

Há atualmente grande interesse no uso desses resíduos, para melhor aproveitar a madeira, processá-los sem perda de qualidade do produto final e, paralelamente, alertar a população sobre a necessidade de um destino apropriado para eles (MIOTTO; DIAS, 2006; PASSEROTTI et al., 2008).

Um exemplo dos materiais à base de madeira são os chamados compósitos plástico-madeira (wood plastic composites - WPC), elaborados a partir da composição de pó de madeira com algum tipo de resina plástica (KOENIG; SYPKENS, 2002), consistindo em um produto inovador, por oferecer acabamento estético e beleza para o ambiente, benefício no consumo e compromisso com a preservação do planeta. Substituem a madeira convencional com significativas melhorias, sendo ecologicamente corretos por possuírem resíduos madeireiros como matéria-prima principal (PASSEROTTI et al., 2008).

Os WPCs têm sido desenvolvidos para diversos fins (STARK, 2001), geralmente caracterizados na flexão (MISSAGIA et al., 2011), apresentando algumas vantagens em relação à madeira maciça, como a de não rachar e não empenar, exigindo ainda pouca ou nenhuma manutenção durante sua vida útil (BRANDT; FRIDLEY, 2003).

$\mathrm{Na}$ indústria de transformação de materiais, estudos desenvolvidos revelam que a utilização por cargas naturais nos materiais compósitos representam um aumento de até $60 \%$ em aplicações dentro da indústria automobilística, principalmente nos materiais que usam o PVC como matriz de fibras naturais (HRISTOV et al., 2004).

Diante dessa evidência, nota-se que a preocupação social e política existente com a proteção do meio ambiente têm-se refletido na defesa elevada de recursos florestais. Assim, a combinação de agentes de reforço naturais e polímeros sintéticos, de modo a fabricar produtos de menor custo que substituam os materiais de madeira tradicionais, oferecem uma gama bem variada de aplicações (PANTHAPULAKKAL; LAW; SAIN, 2005).

Historicamente, o uso de partículas de madeira como reforço em termoplásticos tem sido relatado por inúmeros autores (BLEDZIK et al., 2005).

Khoylou (2006) fabricou e comparou propriedades físicas e mecânicas de materiais compósitos com pastas cimentícias (cimento com areia e água) e serragem de madeira sem espécie definida, impregnados com resina de poliéster insaturado, contendo estireno e/ou metacrilato de metilo (MMA) seguido por exposição à radiação gama de Co-60. Os resultados mostraram que a resistência à compressão e o módulo de elasticidade na flexão foram comparados aos do betão de alta qualidade, sendo sua porosidade significativamente reduzida.

Ashori e Nourbakhsh (2009) investigaram o uso de material reciclado de fibras de madeira e plásticos na confecção de WPCs. Os polímeros utilizados foram o polietileno de alta densidade reciclado e o polipropileno.

O material lignocelulósico para este estudo consistiu em fibras de papel de jornal velho. Os painéis fabricados foram prensados a quente, e a avaliação das propriedades físicas de densidade e absorção de água mostrou que a utilização do polipropileno como agente de acoplamento melhorou a interface entre os elementos constituintes. Foi observado que compósitos feitos de polipropileno de alta densidade promoveram propriedades mecânicas superiores (modulo de elasticidade na flexão de $2 \mathrm{GPa}$ e resistência à flexão de $670 \mathrm{MPa})$ se comparados com compósitos feitos de polipropileno.

Hisham et al. (2011) desenvolveram materiais compósitos em resina epóxi reforçados por resíduos de produtos de madeira obtidos da indústria madeireira originários de vários tipos de madeira em três tamanhos diferentes, sendo caracterizados na tração. A análise de variância acusou ser significativo o tamanho das fibras no módulo de elasticidade e resistência à tração, apresentando os maiores valores os compostos fabricados com as fibras de maior comprimento.

De forma alternativa, os resíduos de madeira têm sido utilizados na fabricação de compósitos destinados a diversas aplicações tecnológicas: na indústria automobilística, na construção civil (reparo e reforço em estruturas), em brinquedos, materiais de uso externo (móveis), bem como também em embalagens em geral (KURUVILLA et al., 1999; AL-QUERISH; SILVA, 1999). 
Ajiwe, Okeke e Ekwuozor (1998) produziram materiais compósitos com resina epóxi, palha de arroz e serragem destinados ao emprego na forma de telha para coberturas residenciais, sendo as propriedades físicas e mecânicas comparadas com as oriundas de telhas cerâmicas fabricadas em escala industrial. Os resultados obtidos indicaram que as propriedades mecânicas na flexão dos materiais fabricados foram compatíveis com as das telhas cerâmicas e que a adição da palha proporcionou redução considerável na absorção de água.

A utilização de plástico reciclado para fabricação de WPCs tem sido estudada por um grande número de autores, com aplicações na forma de pisos externos e internos, vasos, cestas, bancos, mesas, tambores, etc. (AVILA; DUARTE, 2003; JAYARAMAN; BHATTACHARYYA, 2004).

Khoo et al. (2008) fabricaram materiais compósitos com serragem de madeira, resina fenólica e borracha, para ser empregados em colunas de madeira expostas às intempéries, sendo investigas as propriedades: módulo de elasticidade e resistência à compressão. Foram utilizadas duas dimensões médias de partículas de borracha entre $2.515 \mathrm{~mm}$ e $4.826 \mathrm{~mm}$ e duas frações mássicas de resíduos sobre a resina $(10 \%$ e $40 \%)$. Os resultados obtidos das propriedades mecânicas indicaram a viabilidade do emprego dos compósitos fabricados como reparo nas colunas de madeira.

Vijay et al. (2011) desenvolveram materiais compósitos com resina ureia-formaldeído e serragem de madeira para recuperação de pilares (sujeitos às intempéries) de pontes de madeira da estrada de ferro South Branch Valley Railroad (West Virginia, United States). O reparo pôde ser aplicado sem que fosse interrompido o trafego normal na ponte. Depois de fixados os compostos nos pilares danificados, estes foram posteriormente envoltos por um compósito laminado em fibra de vidro. Após a restauração foram realizados ensaios não destrutivos de avaliação. Esses ensaios comprovaram melhoria na resistência e rigidez das colunas reparadas.

Sales, Souza e Almeida (2011) desenvolveram materiais compósitos feitos com resíduos de madeira Pinus, "lodo" resultante da empresa de tratamento de água da cidade de São Carlos (SP, Brasil) e pasta cimentícia (cimento, água e areia). Os resultados obtidos de resistência à compressão, absorção de água e massa específica foram respectivamente iguais a $1,2 \mathrm{MPa}, 8,8 \%$ e 1847 $\mathrm{kg} / \mathrm{m}^{3}$, classificando-os como habilitados para reparos estruturais.

A versatilidade de emprego dos materiais compósitos feitos com resina e serragem é evidenciada pelos trabalhos elencados, podendo ser utilizados na forma de telha, reparo ou reforço em estruturas e móveis em geral, pisos, painéis (aplicações diversas), componentes de peças de veículos automotivos, entre outras, motivando ainda mais o desenvolvimento de novos trabalhos que venham contribuir por firmar o uso de resíduos de madeira na elaboração de novos materiais.

Em linhas gerais, o emprego de fibras naturais como reforço em materiais compósitos tem sido o foco de diversas pesquisas, motivadas na tentativa de substituir os compostos comumente fabricados com reforços sintéticos, por apresentarem as fibras boas relações entre resistência mecânica e peso, aliadas a questões de sustentabilidade.

Resistência e rigidez à flexão e à tração tem sido as propriedades mecânicas mais exploradas nas pesquisas envolvendo os compósitos com resina e fibras de madeira (MISSAGIA et al., 2011), sendo poucos os trabalhos desenvolvidos em que foram investigadas as propriedades de resistência e rigidez na compressão uniaxial.

Pesquisas envolvendo a inclusão de cimento e silicato de magnésio em materiais fabricados com resina e serragem não foram encontradas, e a justificativa do emprego desses materiais na fabricação de compósitos com resina e serragem justifica-se pela possibilidade de incremento nas propriedades mecânicas.

Este trabalho objetivou o desenvolvimento e a caracterização física e mecânica (compressão) de materiais compósitos em matriz epóxi reforçados com serragem de madeira, cimento e silicato de magnésio, possibilitando investigar seu potencial na forma reparo ou reforço em peças ou em estruturas de madeira.

\section{Material e métodos}

Para a avaliação das propriedades físicas e mecânicas dos materiais compósitos fabricados com resina epóxi, serragem de madeira, cimento e silicato de magnésio, foram realizados dois estudos distintos. No primeiro, realizou-se um planejamento experimental apenas com o uso da resina epóxi e da serragem de madeira, e à condição investigada referente ao maior valor do módulo de elasticidade foram incorporadas partículas de silicato de magnésio (talco) e cimento Portland.

Os fatores estipulados no estudo dos compostos fabricados com resina e serragem foram: espécies de madeira (Eucalyptus grandis - eucalipto; Tabebuia serratifolia - ipê), faixa granulométrica (4-10; 50-80 US-Tyler) e fração mássica de 
serragem sobre a resina $(30 \% ; 50 \%)$, conduzindo a um planejamento fatorial completo do tipo $2^{3}$, fornecendo oito condições experimentais (CE) distintas, explicitadas na Tabela 1 , em que TS denota o tipo de serragem, FG a faixa granulométrica e FS a fração de serragem utilizada.

A serragem de madeira de ipê foi também escolhida para o presente estudo por se tratar de uma madeira com maior densidade e melhores propriedades mecânicas quando comparadas às das madeiras de eucalipto, possibilitando verificar se existem diferenças significativas ou não em suas propriedades físicas e mecânicas quando comparadas às dos compostos fabricados com eucalipto.

As variáveis-resposta investigadas nos materiais das oito condições experimentais da Tabela 1 foram: densidade volumétrica $\left(\rho_{v}\right)$, absorção de água em $24 \mathrm{~h}$, módulo de elasticidade na compressão (MOE) e módulo de resistência à compressão (MOR).

A análise de variância (ANOVA) foi empregada para investigar a influência dos fatores individuais (espécies de madeira; faixa granulométrica; fração mássica de serragem), assim como da interação entre ambos nas propriedades físicas e mecânicas de interesse.

Werkema e Aguiar (1996) discutem que a análise da interação entre os fatores envolvidos é mais importante do que a dos fatores individuais, fazendo-se necessário, nestes casos, a investigação apenas dos efeitos de interação. Acusado ser significativo o fator ou a interação entre ambos ( $\mathrm{P}$ valor $<0,05-5 \%$ ) nas respostas investigas pela a ANOVA, foi empregado posteriormente o teste de comparação de Médias de Tukey.

Descoberta entre os oito tratamentos (resinaserragem) a condição de maior valor para o módulo de elasticidade na compressão, a esta foram adicionados separadamente cimento
Portland (CP-V ARI) e silicato de magnésio em duas frações mássicas sobre a resina, sendo de $10 \%$ e $20 \%$. A NOVA foi empregada para verificar a influência da inclusão das duas frações de partículas de cimento no composto de maior MOE (referência), sendo utilizado posteriormente o teste de comparações múltiplas de Tukey para o agrupamento dos níveis do fator fixo considerado significativo pela ANOVA. A mesma abordagem estatística foi empregada para análise da influência da adição das partículas de silicato de magnésio no composto de maior módulo de elasticidade. As variáveis-resposta investigadas destes materiais foram as mesmas dos materiais resina-serragem, com exceção do módulo de resistência à compressão.

\section{Materiais constituintes}

Os resíduos de madeira de eucalipto e de ipê foram peneirados por $5 \mathrm{~min}$ segundo as recomendações da norma americana ASTM D-1921 (AMERICAN... 2012), com o auxílio de um agitador de peneiras (Figura 1a) disponível no Laboratório de Materiais do Departamento de Engenharia Mecânica da UFSJ, de modo a classificar as partículas nas faixas granulométricas 4-10 e 50-80 US-Tyler (Figuras 1b a 1d).

Depois de classificados os resíduos, eles foram conduzidos em estufa para correção do teor de umidade em 12\%, seguindo as premissas e orientações da norma brasileira NBR 7190 (ABNT, 1997) (Projeto de Estruturas de Madeira).

O silicato de magnésio (Figura 2a) e o cimento Portland CP-V ARI (Figura 2b) utilizados na fabricação dos compósitos foram os das marcas VERBAZZA e CAUE respectivamente (MGBrasil), e a resina epóxi escolhida foi a Araldite-M (Figura 3a), da marca Hunstman ${ }^{\circledR}$, juntamente com o endurecedor da marca RenShape HY 956 (Figura 3b).

Tabela 1 - Condições do planejamento experimental para os materiais fabricados com resina e serragem

\begin{tabular}{c|c|c|c}
\hline CE & TS & FG & FS (\%) \\
\hline C1 & eucalipto & $4-10$ & 30 \\
C2 & eucalipto & $4-10$ & 50 \\
C3 & eucalipto & $50-80$ & 30 \\
C4 & eucalipto & $50-80$ & 50 \\
C5 & ipê & $4-10$ & 30 \\
C6 & ipê & $4-10$ & 50 \\
C7 & ipê & $50-80$ & 30 \\
C8 & ipê & $50-80$ & 50 \\
\hline
\end{tabular}

288 Missagia, Z. M. V.; Santos, J. C.; Panzera, T. H. Brandão, L. C.; Silva, D. A. L.; Christoforo, A. L. 
Figura 1 - (a) Agitador de peneiras, (b) serragem de eucalipto nas faixas granulométricas 4-10 e (c) 5080 US-Tyler, e (d) serragem de ipê nas faixas granulométricas 4-10 e (e) 50-80 US-Tyler

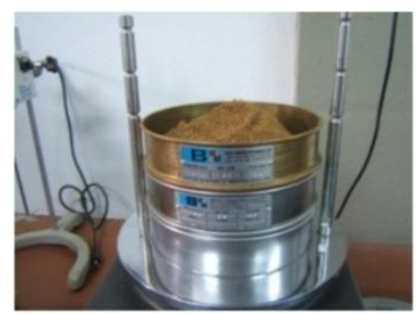

(a)

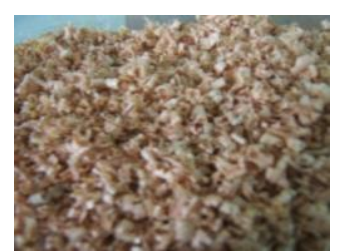

(b)

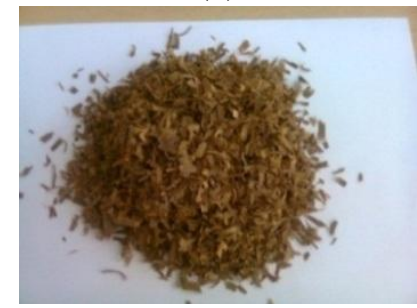

(d)

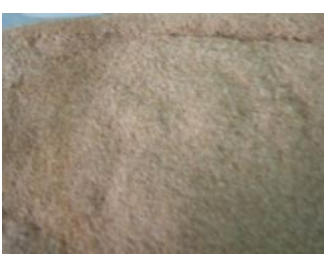

(c)

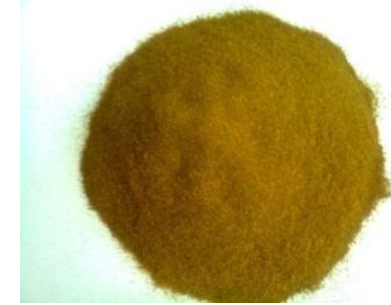

(e)

Figura 2 - (a) Silicato de magnésio e (b) cimento Portland CP-V ARI

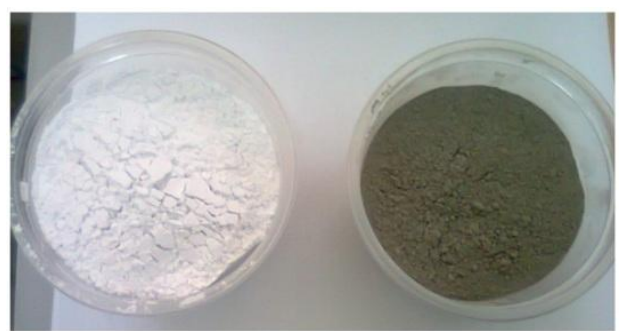

(a)

(b)

Figura 3 - (a) Resina e (b) catalizador

(a)

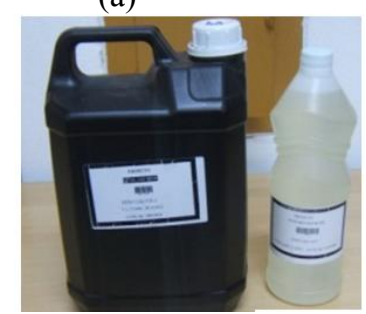

(b)

\section{Mistura dos componentes}

As misturas entre os materiais resina-serragem (Figura 4), resina-serragem-cimento e resinaserragem-talco foram realizadas de forma manual, e as proporções de partículas $30 \%$ e $50 \%$ em fração mássica sobre a resina foram assim definidas após a realização de testes iniciais (misturas entre as fases). Optou-se por utilizar proporções em massa, e não em volume, pela grande variabilidade na densidade da madeira, potencialmente aumentada por se tratar de resíduo. 


\section{Fabricação dos corpos de prova}

Em razão do fato de as propriedades mecânicas investigadas serem obtidas por ensaios de compressão uniaxial e as físicas independerem da forma dos corpos de prova, para ambas as experimentações utilizaram-se amostras de geometrias cilíndricas, com $40 \mathrm{~mm}$ de comprimento $(h)$ e $20 \mathrm{~mm}$ de diâmetro $(d)$, mantendo-se a relação $h=2 \cdot d$ estabelecida pela norma americana ASTM D-695-10:2010.

Depois de misturadas as fases, os materiais resultantes de cada condição experimental foram inseridos manual e gradualmente em tubos de PVC (Figura 5a), com $20 \mathrm{~mm}$ de diâmetro interno e 60 mm de comprimento, devidamente encaixados em um suporte de madeira e compactados com o auxílio de um cilindro de aço torneado (Figura 5b), imprimindo-se uma pressão de aproximadamente $31 \mathrm{kPa}$.

Passados 7 dias (tempo de cura) da inserção dos compostos nos moldes em PVC, eles foram retirados com o auxílio de uma serra elétrica e posteriormente levados para ser faceados (Figura 6).

A Figura 7 ilustra os corpos de prova fabricados nas oito condições experimentais (Tabela 1) referentes aos compostos resina-serragem.

Figura 4 - Mistura manual entre serragem de ipê e resina epóxi

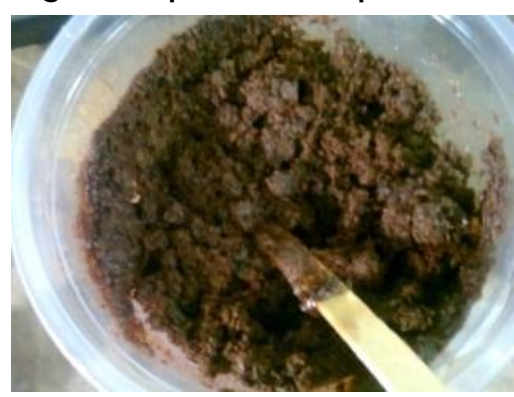

Figura 5 - Formação dos corpos de prova

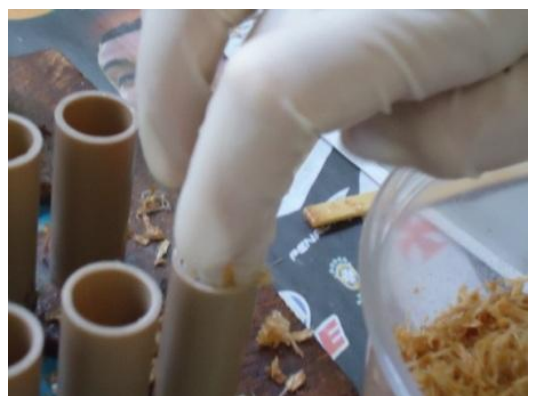

(a) Incerção dos compostos nos tubos de PVC

Figura 6 - Faceamento dos corpos de prova
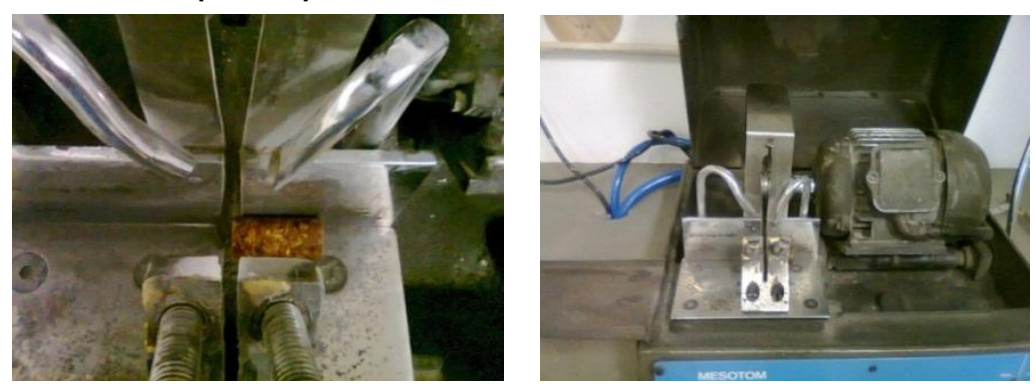
Figura 7 - Compostos fabricados com resina e serragem

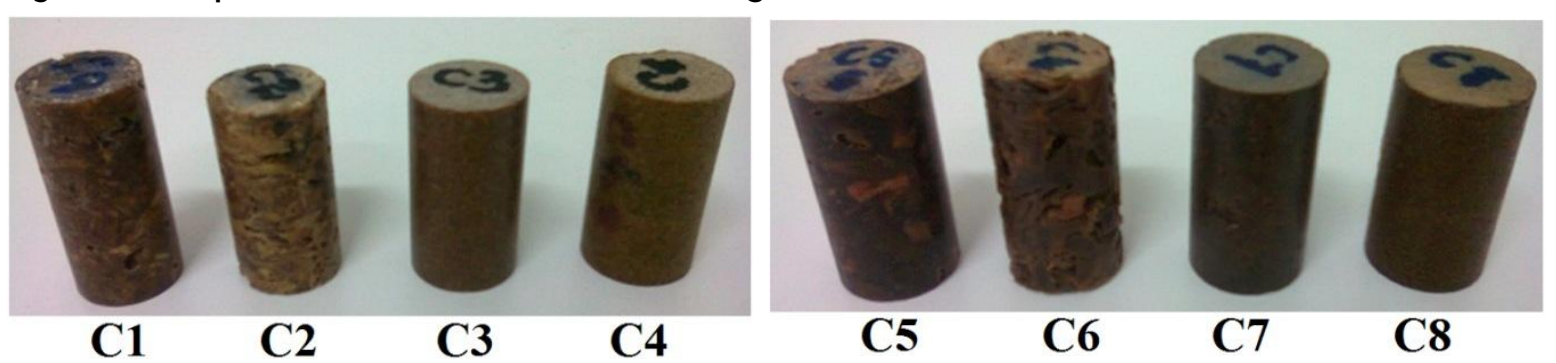

\section{Experimentações}

Para a realização dos testes físicos e mecânicos, por condição experimental (CE) investigada, foram fabricados 14 corpos de prova, 10 destinados aos ensaios de compressão e os 4 restantes para os ensaios de densidade volumétrica e absorção de água após $24 \mathrm{~h}$. Para os compostos resina-serragem foram fabricados 112 corpos de prova, 28 para os compostos resina-serragem-talco e outros 28 para os compósitos resina-serragem-cimento, totalizando 168 corpos de prova, perfazendo um total de 168 experimentações entre testes físicos e mecânicos. Os corpos de prova por condição foram fabricados 5 a 5 , em dias distintos, para os testes mecânicos, e 2 a 2 para os testes físicos (2 réplicas por condição experimental), possibilitando verificar a homogeneidade obtida no processo de confecção dos materiais.

\section{Ensaios mecânicos}

Os ensaios mecânicos (Figura 8) consistiram na obtenção do módulo de elasticidade (MOE) e no módulo de resistência à compressão (MOR). Para tanto, foram utilizadas as premissas e os procedimentos de cálculo descritos pela norma americana ASTM D-695-10 (AMERICAN..., 2010).

O MOE e MOR dos compostos foram obtidos com o uso das Equações 1 e 2 respectivamente, sendo $m$ o coeficiente angular da reta ajustada no trecho linear do diagrama tensãoxdeformação, $F_{\text {máx a }}$ força máxima aplicada, e $S$ a área da seção transversal do corpo de prova.

$$
\begin{aligned}
& M O E=m \\
& M O R=\frac{F_{\text {máx }}}{S}
\end{aligned}
$$

\section{Ensaios físicos}

Como discutido anteriormente, os ensaios físicos consistiram na obtenção da densidade volumétrica $\left(\rho_{v}\right)$ e na absorção de água após $24 \mathrm{~h}\left(\mathrm{~A}_{\mathrm{m}}\right)$, obtidas de acordo com os procedimentos metodológicos das normas EN 323 (EUROPEAN..., 1993) e EN 317 (EUROPEAN..., 1993) respectivamente. Para a obtenção das propriedades físicas foram utilizados um paquímetro digital, uma balança analítica com precisão de $0,01 \mathrm{~g}$ em um sistema a vácuo (Figura 9).

Os corpos de prova, após a imersão em água, ficaram em bomba de vácuo a uma pressão 0,5 bar por $1 \mathrm{~h}$, sendo desligada a bomba e mantida a pressão por $23 \mathrm{~h}$.

A densidade volumétrica (Equação 3) é definida pela razão entre a massa $\left(m_{12 \%}\right)$ e o volume da amostra $\left(v_{12 \%}\right)$ para o teor de umidade de $12 \%$.

$\rho_{v}=\frac{m_{12 \%}}{v_{12 \%}}$

A obtenção da absorção de água após $24 \mathrm{~h}\left(\mathrm{~A}_{\mathrm{m}}\right)$ foi calculada de acordo com a Equação 4, sendo $m_{l}$ e $m_{2}$ respectivamente as massas medidas antes e após a imersão dos corpos de prova em água.

$$
A_{m}(\%)=\frac{m_{2}-m_{1}}{m_{1}} \cdot 100
$$

\section{Resultados e discussões}

\section{Compostos resina-serragem}

Na Tabela 2 apresentam-se os resultados das propriedades físicas e mecânicas dos compostos resina-serragem, sendo $X_{m}$ a média amostral, $D P$ o desvio padrão, e $C V$ o coeficiente de variação. 
Figura 8 - Ensaio de compressão uniaxial

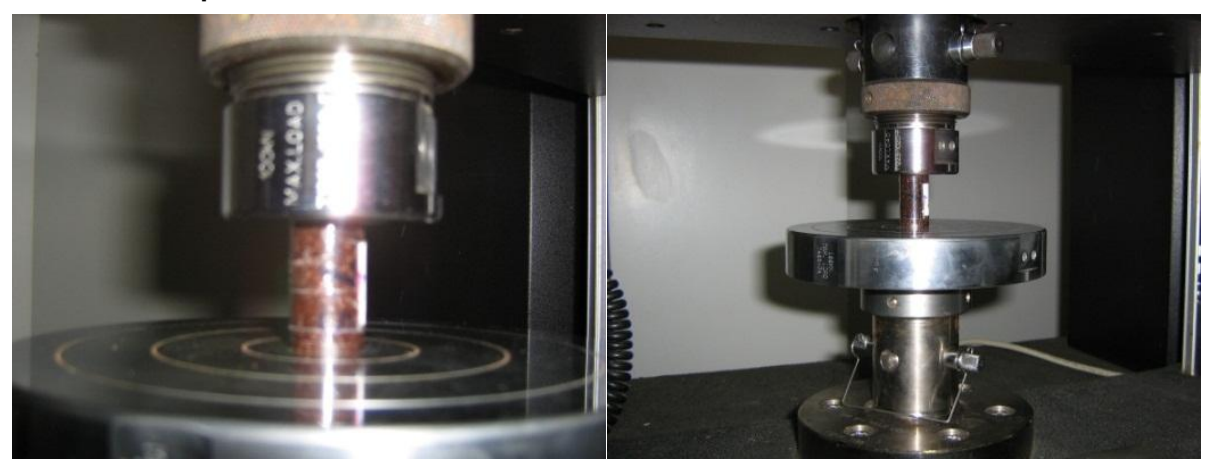

Figura 9 - Submersão de corpos de prova

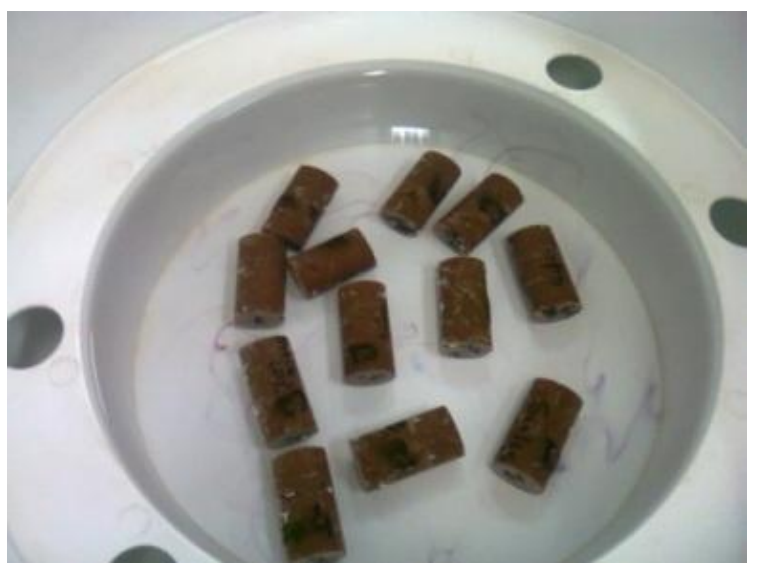

Tabela 2 - Propriedades físicas e mecânicas dos compostos resina-serragem

\begin{tabular}{|c|c|c|c|c|c|}
\hline $\mathbf{C E}$ & Estatísticas & MOE (MPa) & MOR (MPa) & $\rho_{v}\left(\mathrm{~g} / \mathrm{cm}^{3}\right)$ & $A_{m}(\%)$ \\
\hline & $X_{m}$ & 2112 & 58,50 & 0,87 & 1,96 \\
\hline \multirow[t]{2}{*}{ C1 } & $D P$ & 296 & 3,54 & 0,17 & 0,39 \\
\hline & $C V(\%)$ & 14 & 6 & 20 & 20 \\
\hline \multirow{3}{*}{$\mathrm{C} 2$} & $X_{m}$ & 1104 & 36 & 0,94 & 4,01 \\
\hline & $D P$ & 140 & 2,83 & 0,16 & 0,84 \\
\hline & $C V(\%)$ & 13 & 8 & 17 & 21 \\
\hline \multirow{3}{*}{ C3 } & $X_{m}$ & 2540 & 62 & 0,98 & 3,49 \\
\hline & $D P$ & 255 & 11,31 & 0,01 & 0,31 \\
\hline & $C V(\%)$ & 10 & 18 & 2 & 9 \\
\hline \multirow{3}{*}{$\mathrm{C4}$} & $X_{m}$ & 968 & 30 & 0,98 & 5,66 \\
\hline & $D P$ & 125 & 2,12 & 0,14 & 1,07 \\
\hline & $C V(\%)$ & 13 & 7 & 15 & 19 \\
\hline \multirow{3}{*}{ C5 } & $X_{m}$ & 1811 & 44,5 & 1,04 & 2,68 \\
\hline & $D P$ & 143 & 3,53 & 0,08 & 0,43 \\
\hline & $C V(\%)$ & 8 & 8 & 8 & 16 \\
\hline \multirow{3}{*}{ C6 } & $X_{m}$ & 906 & 25 & 1,01 & 3,52 \\
\hline & $D P$ & 65 & 4,24 & 0,09 & 0,54 \\
\hline & $C V(\%)$ & 7 & 17 & 9 & 16 \\
\hline \multirow{3}{*}{$\mathrm{C} 7$} & $X_{m}$ & 1757 & 44 & 1,03 & 3,35 \\
\hline & $D P$ & 192 & 1,41 & 0,05 & 0,65 \\
\hline & $C V(\%)$ & 11 & 3 & 6 & 19 \\
\hline \multirow{3}{*}{ C8 } & $X_{m}$ & 1897 & 43 & 0,97 & 4,70 \\
\hline & $D P$ & 326 & 4,94 & 0,04 & 0,65 \\
\hline & $C V(\%)$ & 17 & 12 & 5 & 14 \\
\hline
\end{tabular}

292 Missagia, Z. M. V.; Santos, J. C.; Panzera, T. H. Brandão, L. C.; Silva, D. A. L.; Christoforo, A. L. 
De acordo com Sales, Souza e Almeida (2011), o valor da resistência à compressão dos compostos fabricados com matriz cimentícia e resíduos oriundos do tratamento de água e de madeira pínus foram em médias iguais a 1,20 $\mathrm{MPa}$, sendo $94,26 \%$ inferior à resistência do concreto convencional (20,9 MPa), classificando os materiais como habilitados para reparos estruturais. Pelos valores médios encontrados das resistências à compressão dos compostos resinaserragem fabricados (25 MPa; $62 \mathrm{Mpa})$, concluise, de acordo com Sales, Souza e Almeida (2011), que esses materiais podem também ser classificados como habilitados para reparos estruturais ou até como reforço, por ser o maior valor de resistência mecânica (C3) 199,66\% superior à resistência do concreto convencional citado pelo mesmo estudo.

A Tabela 3 apresenta os resultados da ANOVA para as propriedades físicas e mecânicas investigadas, encontrando-se sublinhados os $\mathrm{P}$ valores menores que 0,05 , considerados significativos a um nível de confiabilidade de $95 \%$ (WERKEMA; AGUIAR, 1996), sendo TS o tipo de serragem, FG a faixa granulométrica, FS a fração de serragem, e TS*FG, TS*FS, FG*FS e TS*FG*FS as interações entre os fatores.

A Figura 10 apresenta os gráficos de resíduos da ANOVA em relação às propriedades físicas e mecânicas dos compostos resina e serragem, comprovando normalidade nas distribuições dos resíduos pelo fato de os $\mathrm{P}$-valores encontrados serem ambos superiores a 0,05, auxiliando por validar o modelo da ANOVA. A homogeneidade e a independência dos resíduos da análise de variância foram também verificados e satisfeitos em todos os casos, sendo utilizados o gráfico de resíduos versus valores ajustados e o de resíduos versus ordem respectivamente, por resposta investigada, ambos com o auxílio do software Minitab $^{\circledR}$ versão 14. A homogeneidade entre variâncias foi constatada em todos os casos, sendo utilizados os testes de Levene, Bartlett e F-teste.

Tabela 3 - Resultados da ANOVA para os compostos resina-serragem

\begin{tabular}{ccccccccc}
\hline & \multicolumn{10}{c}{ P-valor } \\
\hline Resposta: & TS & FG & FS & TS*FG & TS*FS & FG*FS & TS*FG*FS & R $^{2}$ (Adj.) \\
\hline MOE & 0,380 & $\underline{0,012}$ & $\underline{0,000}$ & 0,127 & $\underline{0,001}$ & 0,242 & $\underline{0,003}$ & $89,47 \%$ \\
MOR & $\underline{0,019}$ & 0,209 & $\underline{0,000}$ & 0,087 & $\underline{0,011}$ & 0,457 & $\underline{0,026}$ & $84,43 \%$ \\
$\rho_{\mathrm{v}}$ & 0,213 & 0,655 & 0,749 & 0,411 & 0,570 & 0,788 & 0,730 & $74,85 \%$ \\
$\mathrm{~A}_{\mathrm{m}} 24 \mathrm{~h}$ & 0,612 & $\underline{0,016}$ & $\underline{0,005}$ & 0,443 & 0,254 & 0,712 & 0,826 & $63,61 \%$ \\
\hline
\end{tabular}

Figura 10 - Gráfico de resíduos da ANOVA sobre as propriedades físicas e mecânicas dos compostos resina-serragem

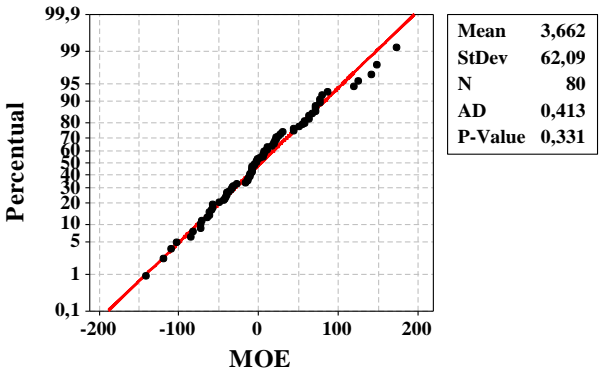

(a) MOE

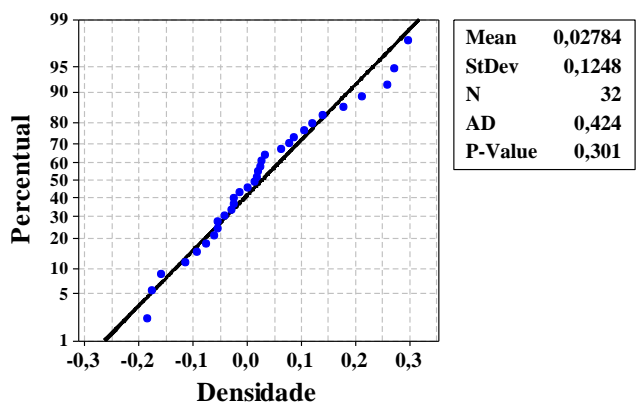

(c) Densidade

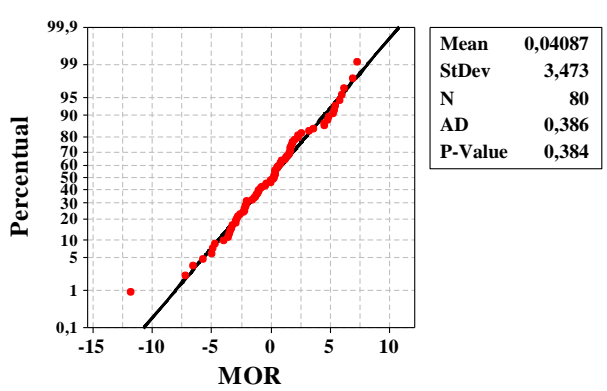

(b) MOR

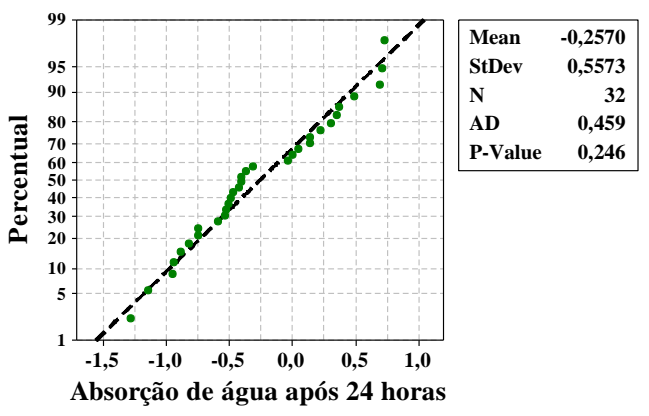

(d) Absorção de água após $24 \mathrm{~h}$ 
Da Tabela 3, nota-se que as interações entre os três fatores investigados para as propriedades MOE e MOR dos compostos resina-serragem foram significativas. As Figuras 11 e 12 ilustram os gráficos de interações dos fatores principais sobre o módulo de elasticidade e de resistência à compressão respectivamente.

Tanto para o MOE quanto para o MOR (interações significativas) foi utilizado o teste de comparações de Tukey, fixando-se cada fator e avaliando-se os efeitos dos respectivos níveis, concluindo das análises efetuadas que os compostos fabricados com $30 \%$ de serragem de madeira de eucalipto na faixa granulométrica US-Tyler 50-80 apresentaram os melhores resultados, assim como pode ser visto na Figura 11, sendo a condição experimental C3 a escolhida na elaboração dos materiais com a adição de cimento Portland CP-V ARI e silicato de magnésio.

Os P-valores da ANOVA sobre a densidade volumétrica mostraram que os fatores individuais e interações não foram significativos, conduzindo a resultados estatisticamente equivalentes. Com relação à absorção de água, apenas os fatores individuais faixa granulométrica e fração de serragem foram significativos. A Figura 13 ilustra os gráficos dos fatores principais para a absorção de água em $24 \mathrm{~h}$.

As Figuras 13a e 13b revelaram que a malha 4-10 e a fração de $30 \%$ de serragem forneceram os melhores valores da absorção de água após $24 \mathrm{~h}$. Os materiais fabricados com uso da malha 4-10 mostraram ser $28 \%$ inferiores aos elaborados da malha 50-80, e os confeccionados com $30 \%$ de serragem foram $38 \%$ inferiores em média aos fabricados com $50 \%$ de serragem.

\section{Compostos resina-serragem-cimento e resina-serragem-talco}

A Tabela 4 apresenta as estatísticas descritivas $\left(X_{m} ; D P ; C V\right)$ dos resultados dos compostos da condição $\mathrm{C} 3$ com as adições de cimento e silicato de magnésio.

Figura 11 - Gráfico de efeitos principais sobre o MOE dos compostos resina-serragem

\section{MOE(MPa)}

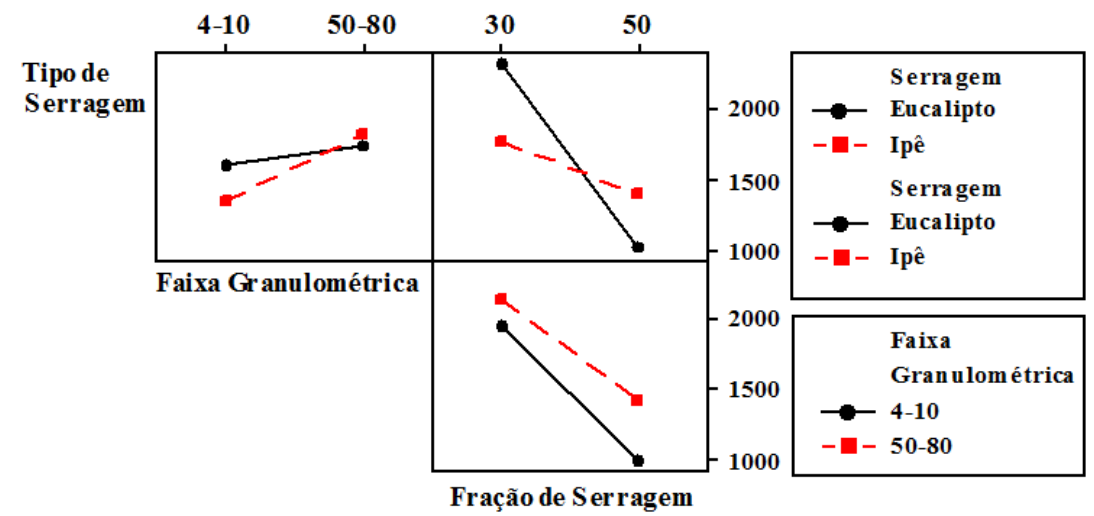

Figura 12 - Gráfico de efeitos principais sobre o MOR dos compostos resina-serragem MOR(MPa)

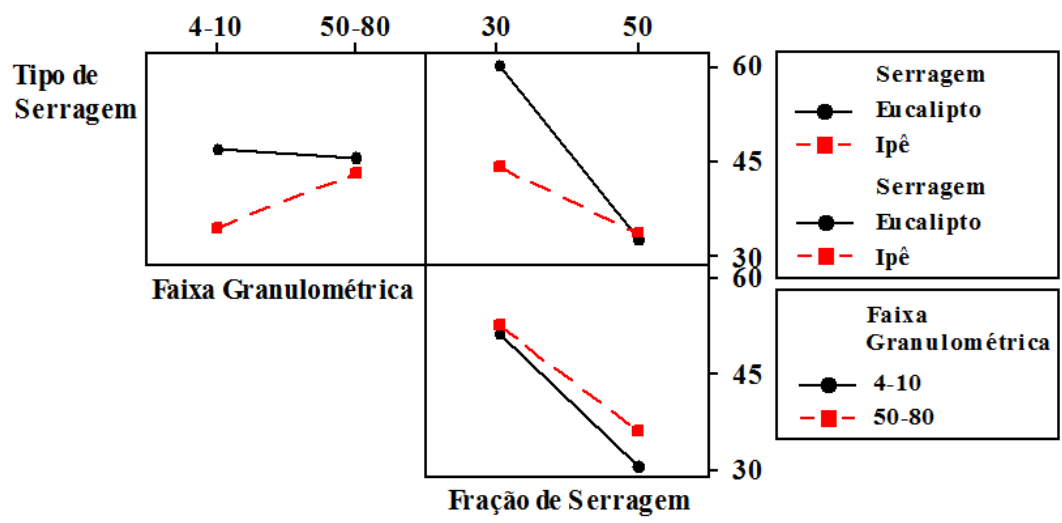

294 Missagia, Z. M. V.; Santos, J. C.; Panzera, T. H. Brandão, L. C.; Silva, D. A. L.; Christoforo, A. L. 
Figura 13 - Gráfico de efeitos principais sobre absorção de água após $24 \mathrm{~h}$

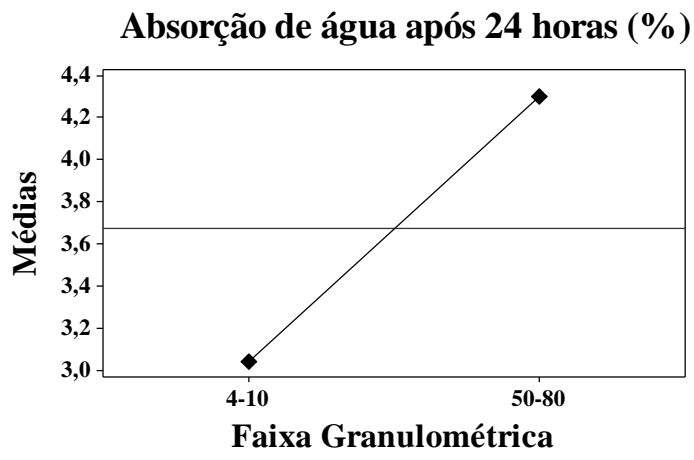

(a) Faixa granulométrica

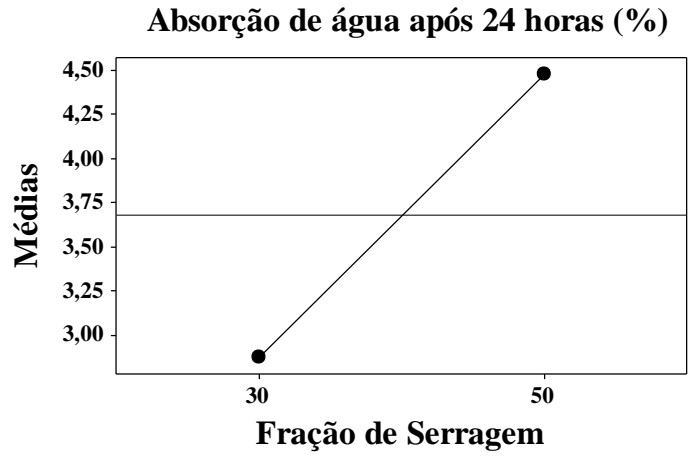

(b) Fração de serragem

Tabela 4 - Resultados das propriedades físicas e mecânicas dos compostos com a adição de cimento e talco

\begin{tabular}{ccccc}
\hline CE & Estatísticas & MOE $(\mathbf{M P a})$ & $\boldsymbol{\rho}_{\mathbf{v}}\left(\mathbf{g} / \mathbf{c m}^{\mathbf{3}}\right)$ & $\mathbf{A}_{\mathbf{m}}(\boldsymbol{\%})$ \\
\hline \multirow{3}{*}{ Cimento (10\%) } & $X_{m}$ & 2616 & 1,08 & 4,22 \\
& $D P$ & 254 & 0,26 & 0,65 \\
& $C V(\%)$ & 10 & 24 & 15 \\
\hline \multirow{3}{*}{ Cimento (20\%) } & $X_{m}$ & 2778 & 1,12 & 4,96 \\
& $D P$ & 381 & 0,18 & 1,32 \\
& $C V(\%)$ & 14 & 16 & 27 \\
\hline \multirow{3}{*}{ Talco (10\%) } & $X_{m}$ & 2370 & 1,11 & 3,78 \\
& $D P$ & 296 & 0,20 & 0,79 \\
& $C V(\%)$ & 13 & 18 & 21 \\
\hline \multirow{3}{*}{ Talco (20\%) } & $X_{m}$ & 2463 & 1,13 & 4,08 \\
& $D P$ & 336 & 0,11 & 0,93 \\
& $C V(\%)$ & 14 & 10 & 23 \\
\hline
\end{tabular}

O P-valor da ANOVA do fator fração de cimento sobre o MOE dos materiais fabricados foi igual a $0,029 \quad\left(\mathrm{R}^{2}\right.$ (Adj. $\left.)=83 \%\right)$ implicando ser significativo o emprego das partículas de cimento no MOE dos compostos. A Figura 14 ilustra o gráfico de resíduos da ANOVA sobre o MOE dos compostos resina-serragem-cimento.

A Figura 15 ilustra o gráfico de efeitos principais do fator frações de cimento sobre o módulo de elasticidade na compressão dos compostos resinaserragem-cimento. A inclusão de $10 \%$ em fração mássica de cimento proporcionou aumento de $4,15 \%$ em relação à condição de referência (C3), sendo $9,70 \%$ superior o MOE dos materiais fabricados com $20 \%$ de cimento em relação aos da condição C3.
A Tabela 5 apresenta os resultados do teste de Tukey do fator fração de cimento sobre o módulo de elasticidade dos materiais fabricados da condição de referência.

$\mathrm{Na}$ Tabela 5, o agrupamento revelou que os materiais fabricados sem e com $10 \%$ de cimento apresentaram resultados equivalentes para o módulo de elasticidade na compressão, sendo não equivalente e superior o MOE dos materiais fabricados com $20 \%$ de cimento em relação aos feitos com $10 \%$ e $0 \%$ desse reforço.

O P-valor da ANOVA para a densidade volumétrica dos materiais fabricados com a adição de cimento foi igual a $0,000 \quad\left(\mathrm{R}^{2}\right.$ (Adj. $\left.)=76 \%\right)$, sendo a inclusão de cimento significativa na densidade dos materiais fabricados. A Figura 16 apresenta o gráfico de normalidade dos resíduos. 
Figura 14 - Resíduos da ANOVA do fator fração de cimento sobre o MOE

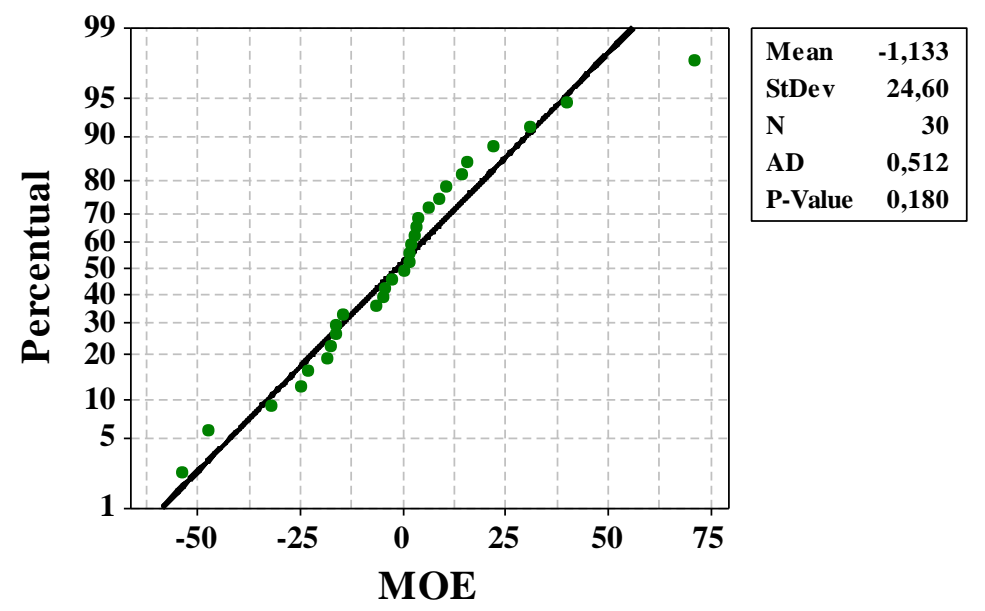

Figura 15 - Gráfico de efeitos principais do fator fração de cimento sobre o MOE

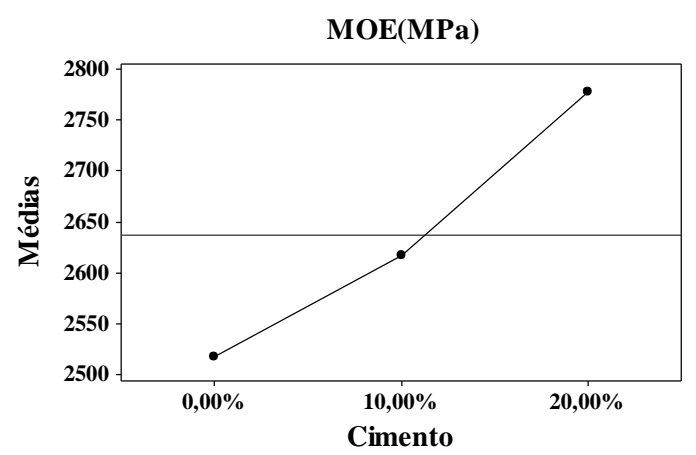

Tabela 5 - Teste de Tukey para o MOE dos materiais com adição de cimento

\begin{tabular}{l|c|c|c}
\hline & $\mathbf{M O E}_{\mathbf{0} \%}$ & $\mathbf{M O E}_{\mathbf{1 0} \%}$ & $\mathbf{M O E}_{\mathbf{2 0} \%}$ \\
\hline Média (MPa) & 2540 & 2616 & 2778 \\
Agrupamento & $\mathrm{B}$ & $\mathrm{B}$ & $\mathrm{A}$ \\
\hline
\end{tabular}

Figura 16 - Gráfico de resíduos da ANOVA sobre a densidade volumétrica dos materiais fabricados com a adição de cimento

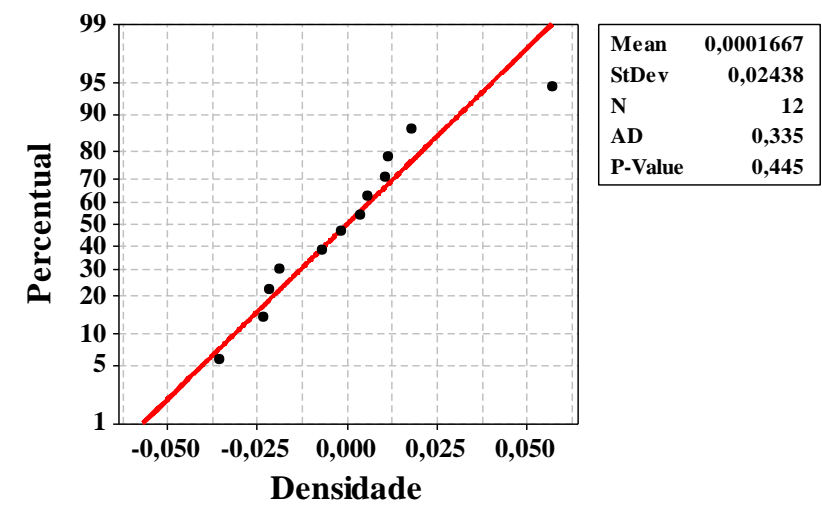

296 Missagia, Z. M. V.; Santos, J. C.; Panzera, T. H. Brandão, L. C.; Silva, D. A. L.; Christoforo, A. L. 
A Figura 17 ilustra o gráfico de efeitos principais do fator frações de cimento sobre a densidade volumétrica dos compostos. A inclusão de $10 \%$ em fração mássica de cimento proporcionou aumento de $13,54 \%$ em relação à condição de referência (C3), sendo $17,70 \%$ superior à $\rho_{v}$ dos materiais fabricados com $20 \%$ de cimento em relação aos da condição C3.

A Tabela 6 apresenta os resultados do teste de Tukey do fator fração de cimento sobre densidade volumétrica dos materiais fabricados da condição de referência. Os resultados indicaram equivalência entre o uso das frações de $10 \%$ e $20 \%$ de cimento nos compostos, apresentando ser não equivalentes (superiores) à condição de referência (menor valor médio).

O P-valor da ANOVA para a absorção de água após $24 \mathrm{~h}$ dos materiais fabricados com a adição de cimento foi igual a $0,000\left(\mathrm{R}^{2}(\mathrm{Adj})=.66 \%\right)$, sendo significativa a inclusão desse reforço. A Figura 18 apresenta o gráfico de normalidade dos resíduos da ANOVA.
A Figura 19 ilustra o gráfico de efeitos principais do fator frações de cimento sobre absorção de água após $24 \mathrm{~h}$ dos compostos. A inclusão de $10 \%$ em fração mássica de cimento proporcionou aumento de $14 \%$ em relação à condição de referência (C3), sendo $36,62 \%$ superior à $\mathrm{A}_{\mathrm{m}}$ dos materiais fabricados com $20 \%$ de cimento em relação aos da condição C3.

A Tabela 7 apresenta os resultados do teste de Tukey do fator fração de cimento sobre absorção de água após $24 \mathrm{~h}$ dos materiais fabricados. Os resultados indicaram que os materiais que apresentaram os maiores valores de $\mathrm{A}_{\mathrm{m}}$ foram os confeccionados com $20 \%$ de cimento, seguidos pelos materiais fabricados com o uso de $10 \%$ e $0 \%$ desse tipo de reforço.

O P-valor da ANOVA do fator fração de silicato de magnésio sobre o MOE dos materiais fabricados sobre a condição de referência C3 foi igual a $0,371\left(\mathrm{R}^{2}\right.$ (Adj.) $\left.=81 \%\right)$, implicando não ser significativo o emprego das porcentagens de talco no MOE dos compostos. A Figura 20 ilustra o gráfico de resíduos obtido da ANOVA.

Figura 17 - Gráfico de efeitos principais do fator fração de cimento sobre densidade volumétrica dos materiais fabricados com cimento

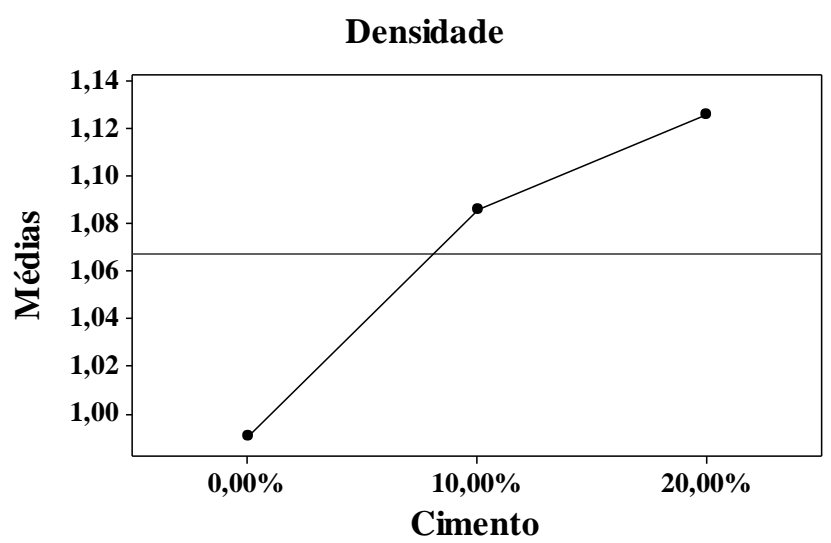

Tabela 6 - Teste de Tukey para a densidade volumétrica dos materiais com adição de cimento

\begin{tabular}{c|c|c|c}
\hline & $\boldsymbol{\rho}_{\mathbf{v} \mathbf{0} \%}$ & $\boldsymbol{\rho}_{\mathbf{v} \mathbf{1 0} \%}$ & $\boldsymbol{\rho}_{\mathbf{v} \mathbf{2 0 \%}}$ \\
\hline Média $\left(\mathrm{g} / \mathrm{cm}^{3}\right)$ & 0,98 & 1,08 & 1,12 \\
Agrupamento & B & A & A \\
\hline
\end{tabular}


Figura 18 - Gráfico de resíduos da ANOVA sobre a absorção de água após 24 h dos materiais fabricados com a adição de cimento
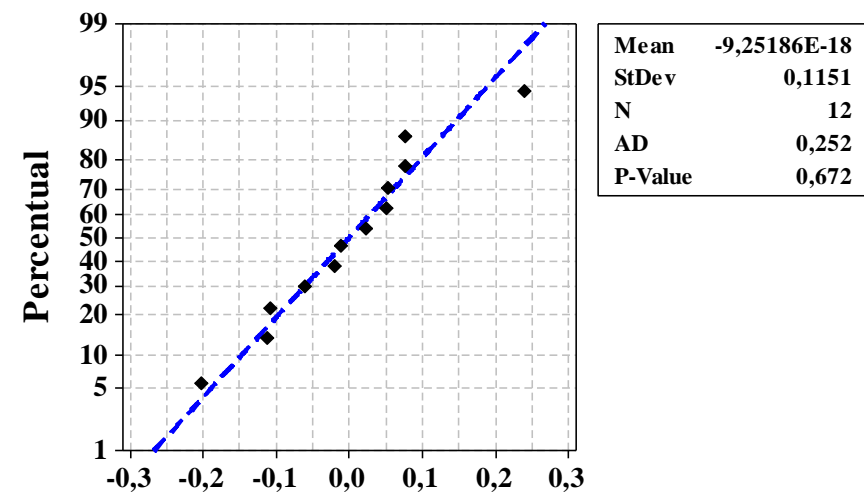

Absorção de água após 24 horas

Figura 19 - Gráfico de efeitos principais do fator fração de cimento sobre a absorção de água após 24 h dos materiais fabricados com cimento

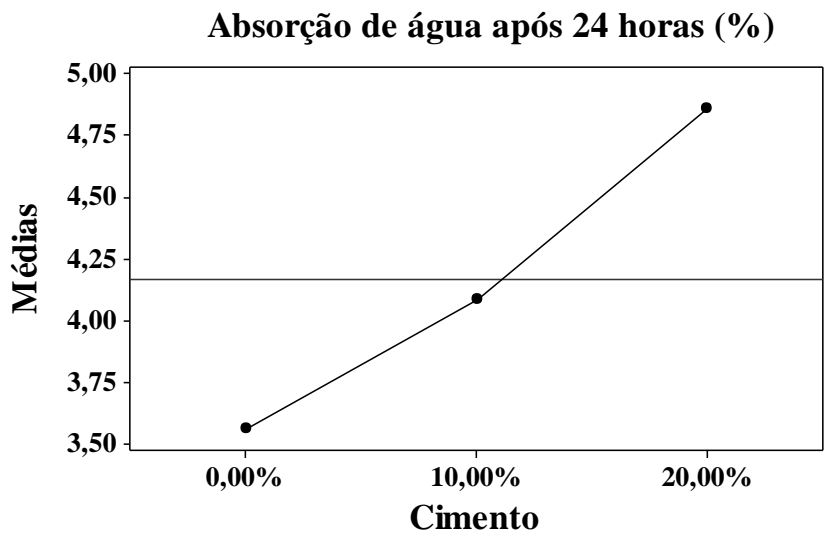

Tabela 7 - Teste de Tukey para a $A_{m}$ dos materiais com adição de cimento

\begin{tabular}{cccc}
\hline & $\mathbf{A}_{\mathbf{m} \mathbf{0 \%}}$ & $\mathbf{A}_{\mathbf{m} \mathbf{1 0} \%}$ & $\mathbf{A}_{\mathbf{m} \mathbf{2 0} \%}$ \\
\hline Média (\%) & 3,49 & 4,22 & 4,96 \\
Agrupamento & $\mathrm{C}$ & $\mathrm{B}$ & $\mathrm{A}$ \\
\hline
\end{tabular}

Figura 20 - Gráfico de resíduos da ANOVA sobre o MOE dos materiais fabricados com a adição de talco

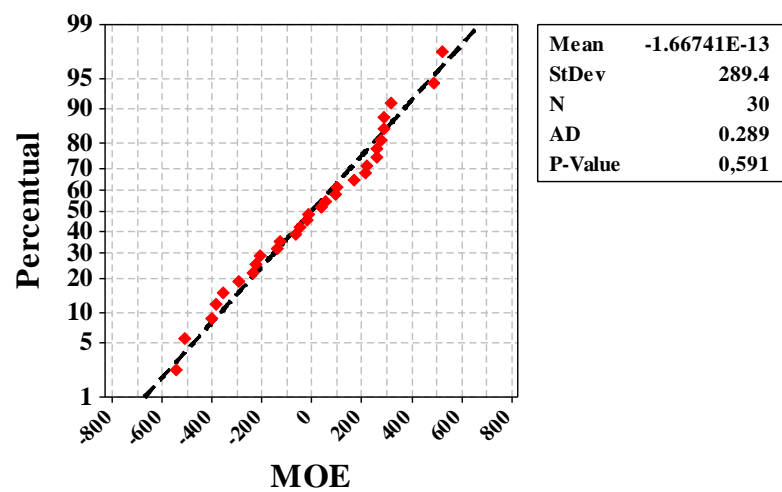

298 Missagia, Z. M. V.; Santos, J. C.; Panzera, T. H. Brandão, L. C.; Silva, D. A. L.; Christoforo, A. L. 
O P-valor da ANOVA do fator fração de silicato de magnésio sobre densidade volumétrica dos materiais fabricados foi igual a 0,192 $\left(\mathrm{R}^{2}\right.$ (Adj.) $\left.=72 \%\right)$, implicando não ser significativo o emprego das partículas de silicato na densidade dos compostos. A Figura 21 ilustra o gráfico de resíduos obtido da ANOVA.

O P-valor da ANOVA do fator fração de silicato de magnésio sobre a absorção de água após $24 \mathrm{~h}$ dos materiais fabricados foi igual a 0,002 $\left(\mathrm{R}^{2}\right.$ (Adj. $\left.)=63 \%\right)$, implicando ser significativo o emprego das partículas de talco na $\mathrm{A}_{\mathrm{m}}$ dos compostos. A Figura 22 ilustra o gráfico de resíduos obtido da ANOVA.

A Figura 23 ilustra o gráfico de efeitos principais do fator frações de talco sobre a absorção de água após $24 \mathrm{~h}$ dos compostos. A inclusão de $10 \%$ em fração mássica de silicato de magnésio proporcionou aumento de $10,73 \%$ em relação à condição de referência (C3), sendo 18,64\% superior à $\mathrm{A}_{\mathrm{m}}$ dos materiais fabricados com $20 \%$ de talco em relação aos da condição C3.

A Tabela 8 apresenta os resultados do teste de Tukey do fator fração de talco sobre a absorção de água após $24 \mathrm{~h}$ dos materiais fabricados da condição de referência. Os resultados indicaram que os materiais com $10 \%$ e $20 \%$ de partículas de talco apresentaram equivalência estatística, sendo maiores que a $\mathrm{A}_{\mathrm{m}}$ dos materiais da condição de referência (menor valor).

Figura 21 - Gráfico de resíduos da ANOVA sobre densidade volumétrica dos materiais fabricados com a adição de talco

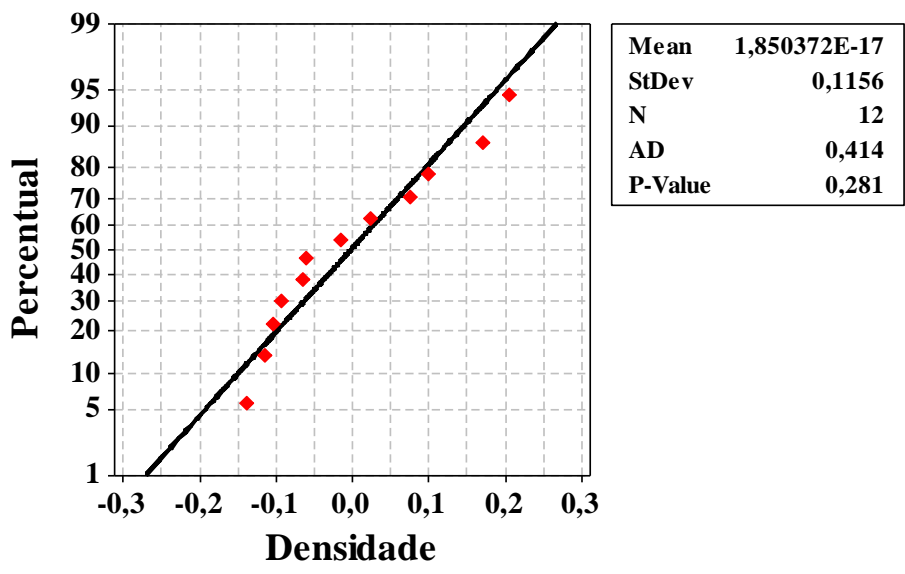

Figura 22 - Gráfico de resíduos da ANOVA sobre a $A_{m}$ dos materiais fabricados com a adição de talco

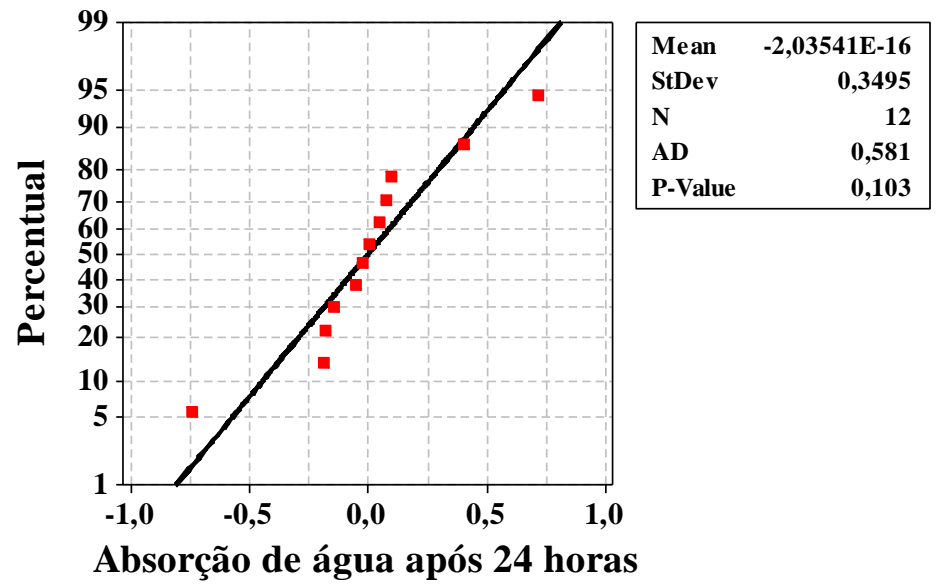


Figura 23 - Gráfico de efeitos principais do fator fração de talco sobre a absorção de água após $24 \mathrm{~h}$

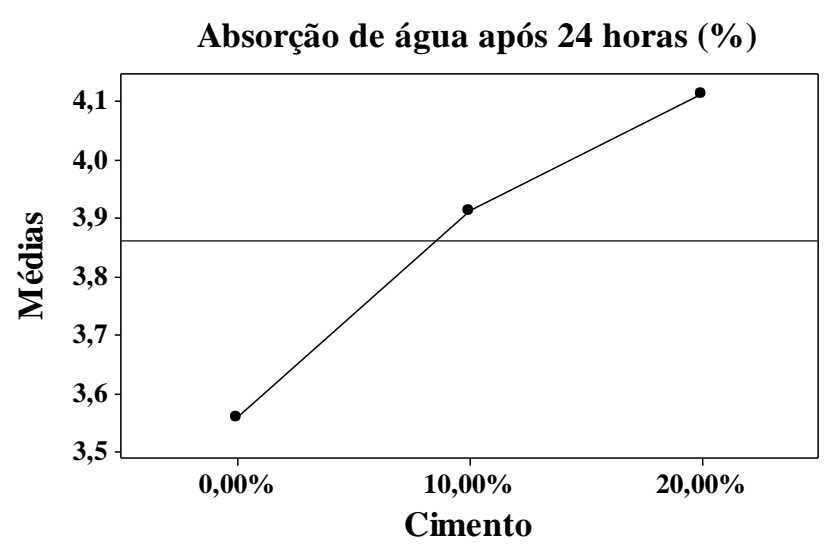

Tabela 8 - Teste de Tukey para a absorção de água após 24 h dos materiais com adição de silicato

\begin{tabular}{cccc}
\hline & $\mathbf{A}_{\mathbf{m} \text { 0\% }}$ & $\mathbf{A}_{\mathbf{m} \mathbf{1 0} \%}$ & $\mathbf{A}_{\mathbf{m} \mathbf{2 0} \%}$ \\
\hline Média (\%) & 3,49 & 3,78 & 4,08 \\
Agrupamento & $\mathrm{B}$ & $\mathrm{A}$ & $\mathrm{A}$ \\
\hline
\end{tabular}

\section{Conclusões}

O processo de fabricação dos compósitos desenvolvidos mostrou ser simples, sendo os materiais obtidos da mistura direta entre as fases. Para a melhoria das propriedades físicas e mecânicas investigadas, utilizou-se de uma peça com a serventia de proporcionar leve compressão, o que pode seguramente ser reproduzido com outros equipamentos no caso da produção e uso desse material para fins específicos.

A incorporação progressiva da serragem conferiu reduções no módulo de elasticidade e na resistência à compressão dos compósitos.

O tipo de serragem (espécie de madeira) foi significativo nas propriedades mecânicas dos compósitos. Os resíduos da madeira de eucalipto, cujo módulo de elasticidade é inferior ao da madeira de ipê, apresentaram os maiores valores das propriedades mecânicas, possivelmente justificada por sua melhor afinidade com a resina epóxi.

As faixas granulométricas e as frações de serragem foram significativas na absorção de água após $24 \mathrm{~h}$ dos materiais resina-serragem fabricados, apresentando os compostos com partículas da malha mais fina e a maior fração mássica de serragem os maiores valores.

Dos compósitos resina-serragem fabricados, o tratamento com $30 \%$ de serragem de madeira de eucalipto e faixa granulométrica 50-80 US-Tyler apresentou os melhores resultados para o módulo de elasticidade na compressão, sendo essa a condição-base (referência) eleita para a inclusão das partículas de cimento e talco.

A inclusão das frações mássicas de cimento mostraram ser significativas em todas as variáveisresposta investigadas, conferindo aumento no módulo de elasticidade à compressão.

A inclusão de partículas de silicato de magnésio nos compostos da condição-base foi significativa apenas na absorção de água após 24 h, não sendo no módulo de elasticidade, nem na densidade volumétrica. Dessa forma, a inclusão de silicato de magnésio nas frações investigadas não se apresentou como boa solução, pois, além de apresentar resultados equivalentes aos dos compostos resina-serragem, possui valor agregado maior do que o da serragem.

Como forma de aplicação dos materiais aqui elaborados, pelas propriedades mecânicas obtidas quando comparadas com as de outras pesquisas envolvendo cimento e serragem, estes podem ser destinados a painéis, reparos estruturais, entre outros.

\section{Referências}

AJIWE, V. I. E.; OKEKE, C. A.; EKWUOZOR, S. C. A Pilot Plant for Production of Ceiling Board From Rice Husks. Biores Technology, v. 66, p. 41-43, 1998.

AL-QURERISH, H. A.; SILVA, J. L. G.

Mechanical Sofwetting System of Natural Fiber

With Polymeric Resin. Journal Processing

Techonology, v. 92, n. 93, p. 124-128, 1999. 
AMERICAN SOCIETY FOR TESTING AND MATERIALS. ASTM D-1921: standard tests methods for particle size (sieve analysis) of rigid plastics. Philadelphia, 2012.

AMERICAN SOCIETY FOR TESTING AND MATERIALS. ASTM D-695-10: standard test method for compressive properties of rigid plastics. Philadelphia, 2010.

ASHORI, A.; NOURBAKHSH, A. Characteristics of Wood-Fiber Plastic Composites Made of Recycled Materials. Waste Management, v. 29, n. 4, p. 1291-1295, 2009.

\section{ASSOCIAÇÃO BRASILEIRA DE NORMAS}

TÉCNICAS. NBR 7190: projetos de estruturas de madeira. Rio de Janeiro, 1997.

AVILA, A. F.; DUARTE, M. V. A Mechanical Analysis on Recycled PET/HDPE Composites. Polymer Degradation and Stability, v. 80, n. 2, p. 373-382, 2003.

BLEDZIK, A. K. et al. A Comparision of Compounding Process and Wood Type For Wood Fibre-pp Composites. Composites Part A: applied Science and Manufacturing, v. 36, p. 789-797, 2005.

BRANDT, C. W.; FRIDLEY, K. J. Effect of Load Rate on Flexural Properties of Wood-Plastic Composites. Wood and fiber Science, v. 35, n. 1, p. 135-147, 2003.

EUROPEAN STANDARD. EN 317:

particleboards and fiberboards: determination of swelling in thickness after immersion in water. Brussels, 1993.

EUROPEAN STANDARD. EN 323: wood base: determination of density. Brussels, 1993.

HISHAM, S. et al. Tensile Properties and Micro Morphologies of Sawdust and Chipwood Filled Epoxy Composites. Key Engineering Materials Composite Science and Technology, v. 4, p. 1070-1074, 2011.

HRISTOV, V. N. et al. Modified Polypropylene Wood Flour Composites. Journal Applied Polymer Science, v. 9, n. 2, p. 1286-1292, 2004.

JAYARAMAN, K.; BHATTACHARYYA, D. Effects of Plasma Treatment in Enhancing the Performance of Woodfibre-Polypropylene Composites. Composites Part A: Applied Science and Manufacturing, v. 35, n. 12, p. 1363-1374, 2004.

KHOO, T. S. et al. Wood Filler-Recycled Polypropylene (WF-RPP) Composite Pallet: study of fastening method. Journal of Reinforced plastics and Composites, v. 27, p. 16-17, 2008.
KHOYLOU, F. Radiation-Induced Polymer Impregnated Sawdust-Clay-Cement Composite. Polymers and Polymer Composite, v. 14, n. 8, p. 826-831, 2006.

KOENIG, K. M.; SYPKENS, C. W. Wood-Plastic Composites For Market Shore. Wood and Wood Products, v. 107, n. 5, p. 49-58, 2002.

KURUVILLA, J. et al. A Review on Sisal Fiber Reinforced Polymer Composites. Revista Brasileira de Engenharia Agrícola e Ambiental, v. 3, n. 3, p. 367-379, 1999.

MIOTTO, J. L.; DIAS, A. A. Reforço e Recuperação de Estruturas de Madeira. Revista Semina: Ciências Exatas e Tecnológicas, Londrina, v. 27, n. 2, p. 163-174, 2006.

MISSAGIA, Z. M. V. et al. Compressive Behaviour of Polimeric Composites Reinforced With Sawdust. In: BRAZILIAN CONFERENCE ON COMPOSITE MATERIAL, 1., Natal, 2011. Proceedings... Natal, 2011.

PANTHAPULAKKAL, S.; LAW, S.; SAIN, M. Enchancement of Processability of Rice-Husk Filled High-Density Polyethylene Profiles. Journal of Thermoplastic composite Materials, v. 18, n. 5, p. 445-458, 2005.

PASSEROTTI, G. F. A. et al. Caracterização e Produção de Painel Particulado de Eucalyptus sp. Utilizando Adesivo Poliuretano. In: CONGRESSO BRASILEIRO DE ENGENHARIA E CIÊNCIAS DOS MATERIAIS, 18., Porto de Galinhas, 2008. Anais... Porto de Galinhas, 2008.

SALES, A.; SOUZA, F. R.; ALMEIDA, F. C. R. Mechanical Properties of Concrete Produced With a Composite of Water Treatment Sludge and Sawdust. Construction and Building Materials, v. 25, p. 2793-2798, 2011.

STARK, N. Influence of Moisture Absorption on Mechanical Properties of Wood FlourPolypropylene Composites. Journal of Thermoplastic Composite Materials, v. 14, n. 5, p. 421-432, 2001.

VIJAY, P. V. et al. Rapid Restoration of Rail Road Timber Bridges Using Polymer Composites. In: TECHNICAL CONFERENCE OF THE SOCIETY OF PLASTICS ENGINEERS, 69., Pittsburgh, 2011. Proceedings... Pittsburgh, 2011.

WERKEMA, M. C. C.; AGUIAR, S.

Planejamento e Análise de Experimentos: como identificar e avaliar as principais variáveis influentes em um processo., Belo Horizonte: Fundação Christiano Ottoni, Escola de Engenharia da UFMG 1996. 
YAMAJI, F. M.; BOUDELLE, A. Utilização da

Serragem na Produção de Compósitos Plástico

Madeira. Revista Floresta, Curitiba, v. 39, n. 1, p.

54-66, 2004.

Zélia Maria Velloso Missagia

Departamento de Engenharia Mecânica | Universidade Federal de São João Del-Rei | Praça Frei Orlando, 170, Campus Santo Antônio, São João del Rei | São João Del Rei - MG - Brasil | CEP 36300-000 | Tel.: (32) 3379-2395 | E-mail: zmissagia@hotmail.com

Júlio Cesar Santos

Departamento de Engenharia Mecânica | Universidade Federal de São João Del-Rei | E-mail: sanjulio2000@yahoo.com.br

Túlio Hallak Panzera

Departamento de Engenharia Mecânica | Universidade Federal de São João Del-Rei | -mail: panzera@ufsj.edu.br

Lincoln Cardoso Brandão

Departamento de Engenharia Mecânica | Universidade Federal de São João Del-Rei | Tel.: (32) 3379-2606 | E-mail: lincoln@ufsj.edu.br

\section{Diogo Aparecido Lopes Silva}

Escola de Engenharia | Universidade de São Paulo | Av. Trabalhador São Carlense, 400, Centro | São Carlos - SC - Brasil | CEP $13566-590$ | Tel.: (16) 3373-9369 | E-mail: diogo.apls@gmail.com

\section{André Luis Christoforo}

Departamento de Engenharia Mecânica | Universidade Federal de São João Del-Rei | Tel.: (32) 3379-2600 |

E-mail: alchristoforo@gmail.com

\section{Revista Ambiente Construído}

Associação Nacional de Tecnologia do Ambiente Construído

Av. Osvaldo Aranha, $99-3^{\circ}$ andar, Centro

Porto Alegre - RS - Brasil

CEP $90035-190$

Telefone: +55 (51) 3308-4084

Fax: +55 (51) 3308-4054

www.seer.ufrgs.br/ambienteconstruido

E-mail: ambienteconstruido@ufrgs.br 